\title{
MECANISMOS REGIONAIS DE CONTROLE DA PROLIFERAÇÃO DE ARMAS NUCLEARES - A PROPOSTA DE UMA ZONA LIVRE DE ARMAS NUCLEARES NO ORIENTE MÉDIO
}

\section{Adalgisa Soares/ Davi Leite/ José Costa Filho/}

\author{
Nayara Furtado ${ }^{1}$
}

\begin{abstract}
Resumo
O presente artigo trata dos mecanismos regionais de controle da proliferação de armas nucleares, mais especificamente da proposta de uma Zona Livre de Armas Nucleares (ZLAN) no Oriente Médio. Em primeiro lugar, traça-se um breve histórico sobre o regime de não-proliferação nuclear e sobre as propostas bem sucedidas para a criação de ZLANs em outras regiões do mundo. Em seguida, é feita uma revisão ou um reexame da história recente do Oriente Médio desde a criação do Estado de Israel, com foco nos episódios relacionados à violação do regime de não proliferação nuclear e às iniciativas para o desarmamento. Este artigo argumenta que a criação de uma ZLAN no Oriente Médio depende da colaboração das potências nucleares globais e regionais, no sentido de não ameaçar os países desta área e garantir sua segurança, da elaboração de políticas nacionais que incluam atores não-estatais, principalmente aqueles entendidos como ameaça à segurança e estabilidade na região, e da plena
\end{abstract}

\footnotetext{
${ }^{1}$ Adalgisa Bozi Soares é estudante de Graduação do curso de Relações Internacionais da Universidade de Brasília (UnB) e membro do Pet/Rel (Programa de Educação Tutorial em Relações Internacionais); Davi Marco Lyra Leite é estudante de Graduação do curso de Engenharia Elétrica da Universidade de Brasília (UnB); José Joaquim Gomes da Costa Filho é estudante de Graduação do curso de Relações Internacionais da Universidade de Brasília (UnB) e membro do Grupo de Análise de Prevenção de Conflitos Internacionais GAPCon; Nayara Frutuoso Furtado é estudante de Graduação do curso de Relações Internacionais da Universidade de Brasília (UnB).
} 
adesão de todos os países membros da região, bem como de seus vizinhos, aos mecanismos de não proliferação já existentes. Na conclusão, o artigo salienta que, embora seja claro que a criação de uma ZLAN esteja distante de ser concretizada, em razão da conjuntura política da região, o esforço neste sentido por parte de todos os atores envolvidos garantiria um ambiente mais seguro para a busca de solução de outras inseguranças no Oriente Médio.

Palavras-Chave: Não-Proliferação Nuclear; Oriente Médio; Zona Livre de Armas Nucleares.

\begin{abstract}
The present article addresses the regional mechanisms to control the proliferation of nuclear weapons, more specifically the proposal to create a Nuclear Weapon Free Zone (NWFZ) in the Middle East. First, the article draws a background on the non-proliferation regimen and the successful proposals to the creation of NWFZ in other regions of the world. After, the article revises the recent history of the Middle East, from the creation of the State of Israel, emphasizing the episodes related to the violation of the nonproliferation regimen and the disarmament initiatives. This article states that the creation of a NWFZ in the Middle East depends on the collaboration of the nuclear and regional powers, in the sense of not threatening and guaranteeing the security of middle eastern countries, also depends on the elaboration of national policies that include non-state actors, especially those regarded as a threat to stability and security of the region, and finally, also depends on the full compliance, by every state in the region, with the non-proliferation mechanisms that already exist. At the conclusion, the article lays stress upon the fact that, even though the creation of a NWFZ in the Middle East seems unlikely at the moment, international, national and sub national actors should commit to this goal in order to produce a safe environment to the addressing of other insecurities in the Middle East.
\end{abstract}

Keywords: Non-proliferation of nuclear weapons; Middle East, Nuclear Weapon Free Zone 


\title{
Introdução
}

\begin{abstract}
"O desenvolvimento de Zonas Livres de Armas Nucleares, nas últimas quatro décadas, é uma prova do que as nações podem fazer, região por região, para atingir objetivos comuns de segurança". Dr. Mohamed ElBaradei, Diretor-Geral da AIEA, 2005. ${ }^{2}$
\end{abstract}

\begin{abstract}
A ideia do estabelecimento de Zonas Livres de Armas Nucleares (ZLAN) remonta ao ano de 1958 (Goldblat, 1997, p.18). Trata-se de zonas geograficamente delimitadas, geralmente em nível regional, nas quais países comprometem-se com a não produção, aquisição, teste ou posse de armas nucleares. Já com a primeira demonstração dos Estados Unidos do poder destruidor dos armamentos nucleares em Hiroshima e Nagasaki (1945), a proliferação tornou-se questão central nos debates sobre segurança internacional. O fim da Guerra Fria não acaba com a preocupação em relação à proliferação, e sim adiciona novos elementos a esta discussão.
\end{abstract}

Enquanto, no período anterior à queda do Muro de Berlim, a principal preocupação era a contenção nuclear das duas super potências, o cenário internacional atual traz novas inquietações. Por um lado, vários fatores, como o aquecimento global, geram demanda por fontes alternativas de energia e, por conseguinte, fazem com que se retomem as discussões sobre o desenvolvimento da energia nuclear. Com isso, é despertado nas potências nucleares ${ }^{3}$ o temor de

${ }^{2}$ Statement of the Director General. México, 2005. Livre tradução dos autores. Disponível em: <http://www.iaea.org/NewsCenter/Statements/2005/ebsp2005n005.html> Acesso em: 02 abr. 2010.

${ }^{3} \mathrm{O}$ termo potência ou potência nuclear foi utilizado no texto como sinônimo de Estado possuidor de armas nucleares e meios para utilizá-las. 
que essa demanda poderá reacender velhas ambições de alguns países não-nucleares de construção de programas nucleares clandestinos. Por outro, a ameaça do terrorismo internacional torna a proliferação um assunto ainda mais delicado. Teme-se que, por razões de ineficiência no controle interno e/ou externo, organizações terroristas possam ter acesso a armas ou materiais nucleares.

Independentemente das razões alegadas em relação à preocupação acerca da referida proliferação, é certo que a possibilidade de destruição instantânea, decorrente do uso de tecnologia nuclear para fins bélicos, tem efeitos devastadores em regiões instáveis do planeta. Nesse sentido, a proposta da criação de uma Zona Livre de Armas Nucleares, que leve em conta as peculiaridades do Oriente Médio, surge como uma solução para a persistente situação de conflito na região. Esta zona permitiria aos países da região a possibilidade de uma convivência mais pacífica e com menor hostilidade, além de ser um passo importante para a o estabelecimento de relações de confiança mútua na conturbada região.

O Regime de Não-Proliferação Nuclear e as Zonas Livres de Armas Nucleares

As Zonas Livres de Armas Nucleares são uma ideia que surge como forma de controle da proliferação de armas nucleares, à medida que aumentam as tensões nucleares no mundo. As discussões para o banimento destas armas iniciaram-se logo após os ataques americanos a Hiroshima e Nagasaki (1945). Em agosto de 1949, a União Soviética detonou um artefato nuclear, tornando-se, ao lado dos Estados Unidos, uma potência nuclear. Somente três anos depois do teste soviético, os britânicos explodiram seu primeiro artefato nuclear (Marzo \& Almeida, 2006). 
Neste cenário marcado pela crescente bipolarização entre os blocos socialista e capitalista e pela disseminação de armas nucleares, a União Soviética introduziu na Assembléia Geral das Nações Unidas, em 1956, a ideia de criação de uma Zona Livre de Armas Nucleares (ZLAN) na Europa Central. Esta superpotência temia que os EUA e a Grã-Bretanha pudessem estacionar armamentos nucleares muito próximos das fronteiras de sua área de influência na Europa. A ideia, por suas grandes implicações geopolíticas na Guerra Fria, não foi levada adiante. Neste mesmo ano, foi criada a Agência Internacional de Energia Atômica (AIEA). Esta instituição tornar-se-ia muito importante na história da não-proliferação de armas nucleares ${ }^{4}$.

Em 1958, surge uma nova proposta de criação de uma ZLAN na Europa Central, formulada pelo ministro das Relações Exteriores polonês, Adam Rapacki. Esta proposta ficou conhecida como Plano Rapacki e nasceu da preocupação polonesa em relação ao deslocamento de armas nucleares americanas para a Alemanha Ocidental e de armas nucleares soviéticas para o território polonês. A zona abrangeria a Polônia, antiga Tchecoslováquia, Alemanha Oriental e Ocidental e outros países europeus. No entanto, a rivalidade entre os EUA e a URSS mais uma vez impediu o sucesso da proposta. Vale ressaltar que o fracasso deste plano não impediu que ele fosse utilizado como base para os que vieram depois. Da mesma forma, outras propostas surgiram no Norte da Europa e na Região Mediterrânea durante os anos 1960 e fracassaram (Bahgat, 2007, p.162).

A década de 1960 foi marcada ainda por outros acontecimentos importantes para a evolução da política nuclear global. Em fevereiro de 1960, a França realizou seu primeiro teste nuclear em Reganne, na

${ }^{4}$ Para mais informações sobre a AIEA, veja <www.iaea.org> Acesso em: 02 abr. 2010. 
Argélia. O impulso para o desenvolvimento de seu programa nuclear estratégico próprio veio da humilhação causada pela Crise do Canal de Suez (1956)5. Quatro anos após a França tornar-se uma potência nuclear, a China detonou sua primeira bomba atômica. Em 1964, já estava formado o grupo de potências nucleares que posteriormente foi reconhecido pelo Tratado de Não Proliferação Nuclear.

Esta década, além de representar um momento de maior proliferação da tecnologia nuclear militar, presencia dois grandes passos para o controle de armas nucleares: a criação da Zona Livre de Armas Nucleares na América Latina e Caribe e a redação do Tratado de Não-Proliferação Nuclear (TNP). Este último é a pedra fundamental no combate à proliferação de armas nucleares. Após 43 ratificações, o TNP entrou em vigor em 1970. Ele reconhece a existência de apenas cinco potências nucleares: China, França, a Grã-Bretanha, os Estados Unidos da América e a URSS (depois de 1991, a Federação Russa herda este status) ${ }^{6}$. Em linhas gerais, dispõe que somente as cinco potências nucleares reconhecidas podem possuir armas nucleares e, em contrapartida, têm obrigação de transferir tecnologia nuclear para fins pacíficos aos demais membros do tratado e de continuar as discussões sobre o desarmamento nuclear total. (TNP, 1968).

Diferentemente do TNP, a ZLAN na América Latina e Caribe tem alcance regional. Mais conhecido como Tratado de Tlatelolco, cidade mexicana onde foi assinado, este acordo representa a concretização da primeira ZLAN que logrou sucesso na sua implementação prática. Em 1962, durante a Crise dos Mísseis de Cuba, o Brasil

\footnotetext{
${ }^{5}$ A Crise do Canal de Suez desencadeou-se com a invasão, por parte da Inglaterra, França e Israel, da Península do Sinai e do Canal de Suez, que havia sido nacionalizado pelo governo egípcio. Em 1959, apesar da derrota egípcia, os países invasores, em razão da intervenção dos EUA e da antiga URSS no conflito, foram obrigados a se retirarem da região.

${ }^{6}$ A República Popular da China e a França só aderiram ao TNP em março e agosto de 1992, respectivamente.
} 
submeteu à Assembléia Geral das Nações Unidas uma proposta de criação de uma ZLAN na América Latina. Essa proposta não chegou sequer a ser votada (Goldblat, 1997, p.19). No ano seguinte, o México, com o apoio de outros cinco países latino-americanos, reapresentou uma proposta de ZLAN na América Latina e obteve o apoio da Assembléia Geral das Nações Unidas. Depois de alguns anos de negociações, o Tratado de Tlatelolco ${ }^{7}$ foi assinado em 1967. Dois anos depois, a ZLAN da América Latina e Caribe entrou em vigor. Cuba foi o último país a ratificar o documento, fato ocorrido apenas em 2002.

O Tratado de Tlatelolco proíbe o teste, uso, manufatura, produção ou aquisição de armas nucleares por qualquer meio, assim como o recebimento, armazenamento, instalação, emprego ou qualquer forma de posse de armas nucleares. Além disso, estabeleceu-se um sistema de controle e uma instituição para implementá-lo: o Organismo para a Proscrição de Armas Nucleares na América Latina (OPANAL). O Protocolo I deste tratado é direcionado aos países que possuem territórios na região: Estados Unidos, França, Holanda e Grã-Bretanha. Estes são chamados a respeitarem a ZLAN. Já o Protocolo II conclama as potências nucleares a se comprometerem a não interferir no alcance dos objetivos do tratado (Marzo \& Almdeida, 2006, p.51).

Após o pioneirismo latino-americano, mais de quinze anos se passaram até a implementação de outra ZLAN. Esta se deu por meio do Tratado de Rarotonga, que estabeleceu a Zona Livre Nuclear do Pacífico Sul. As discussões acerca desta zona tiveram início com uma proposta da Nova Zelândia ao Fórum do Pacífico Sul (SPF, sigla em

\footnotetext{
${ }^{7}$ Para mais informações veja <http://www2.mre.gov.br/dai/tlatelolco.htm> Acesso em: 24 Nov. 2007.
} 
inglês), ainda em 1975. No entanto, esta ideia somente ganhou força com a renovação da proposta por parte da Austrália ao SPF, em 1983, como resultado da insatisfação com as atividades, principalmente, testes das potências nucleares na região (Goldblat, 1997, p.22).

Em 6 de agosto de 1985, foi assinado o Tratado da Zona Livre Nuclear do Pacífico Sul ${ }^{8}$ em Rarotonga, Ilhas Cook. Entrou em vigor, com a oitava ratificação, em dezembro de 1986. Este tratado proíbe tanto a fabricação, aquisição, posse e o controle de qualquer artefato nuclear explosivo9, quanto à procura ou ao recebimento de assistência para a fabricação ou aquisição destes por parte dos países membros (Marzo; Almeida, 2006, p.106). Adicionalmente, os signatários comprometeram-se a não apoiar ou fomentar a fabricação, aquisição ou teste de qualquer artefato nuclear explosivo por outro Estado. Vale ressaltar ainda que este tratado também impõe a seus signatários um compromisso de que não lançarão rejeitos e materiais radioativos no mar situado dentro da zona. Por isso, a Zona Livre Nuclear do Pacífico Sul vai além de uma "Zona Livre de Armas Nucleares".

De acordo com o Tratado de Rarotonga, os países membros devem assinar um acordo de salvaguardas abrangentes com a Agência Internacional de Energia Atômica e apoiar continuamente o TNP. O Protocolo I é direcionado aos países que possuem territórios situados na região: França, Reino Unido e Estados Unidos, obrigando-os a respeitarem os objetivos do tratado. O Protocolo II, por sua vez, possui a mesma obrigação, mas é voltado para as cinco potências nucleares. Já o Protocolo III proíbe as mesmas cinco potências de

\footnotetext{
${ }^{8}$ Veja <http://www.state.gov/t/ac/trt/5189.htm> Acesso em 01 nov. 2007.

9 Neste caso, "artefato nuclear explosivo" é qualquer artefato explosivo capaz de liberar energia nuclear independentemente de seu propósito. Além disso, o termo inclui artefatos desmontados ou parcialmente montados, mas desconsidera seu meio de transporte ou propulsão.
} 
realizarem testes nucleares na região. Apenas os Estados Unidos não ratificaram os Protocolos I, II e III (Marzo \& Almeida, 2006, p.107).

Dez anos após o estabelecimento da Zona do Pacífico Sul, foi assinado, em Bangkok, o tratado de criação da Zona Livre de Armas Nucleares do Sudeste Asiático. Este tratado abrange os territórios de Brunei Darussalam, Camboja, Filipinas, Indonésia, Laos, Malásia, Mianmar, Cingapura, Tailândia e Vietnã. A proposta para criação da ZLAN tem suas origens na Declaração da Zona de Paz, Liberdade e Neutralidade da Associação das Nações do Sudeste Asiático (ASEAN) de 1971. Ela ganhou força com o fechamento das bases militares americanas nas Filipinas (Goldblat, 1997, p.27). Segundo o Tratado de Bangkok, como ficou conhecido, reconhece-se a proibição aos seus signatários de desenvolverem, testarem, fabricarem, adquirirem, possuírem ou terem controle sobre armas nucleares ${ }^{10}$. Além disso, é proibido o estacionamento de armas nucleares na zona.

Uma novidade trazida por este tratado é a inclusão na zona das plataformas continentais e das Zonas Econômicas Exclusivas (ZEE dos signatários. As potências nucleares são contra esta maior abrangência territorial da ZLAN do Sudeste Asiático e, por isso, nunca assinaram ou ratificaram o Protocolo a elas destinado. Mesmo assim, com a sétima ratificação, o Tratado de Bangkok ${ }^{11}$ entrou em vigor em março de 1997 (Marzo \& Almeida, 2006).

Recentemente, foi criada a última ZLAN, que abrange os territórios do Cazaquistão, Quirguistão, Tajiquistão, Turquemenistão e Uzbequistão, na Ásia Central. Esta zona vinha sendo discutida desde

\footnotetext{
${ }^{10}$ Neste tratado, arma nuclear refere-se a qualquer artefato explosivo capaz de liberar energia nuclear.

${ }^{11}$ Treaty on the Southeast Asia Nuclear Weapon-Free Zone Bangkok. Tailândia, 1995. Disponível em: 〈http://www.aseansec.org/2082.htm> Acesso em: 01 Nov. 2007.
} 
1997, mas o Tratado $^{12}$ só foi assinado em 2006 na cidade de Semipalatinsk, Cazaquistão. Ela encontra-se numa região estratégica, pois está rodeada pela China, Índia, Irã e Rússia, países muito importantes no cenário global da proliferação nuclear (The UN Disarmament Yearbook, 2007, p.164).

Os estados signatários deste tratado comprometem-se a não desenvolver, produzir, estocar, adquirir e possuir qualquer artefato nuclear explosivo. Eles também aceitaram submeter seu material nuclear às salvaguardas da AIEA. Além disso, deve-se ressaltar que, no escopo desta zona, enquadram-se preocupações com a proteção do meio ambiente em relação aos materiais nucleares (Bahgat, 2007, p.163).

A África também possui um tratado sobre a implantação de uma Zona Livre de Armas Nucleares Africana. No entanto, este tratado ainda não entrou em vigor porque não alcançou o número mínimo de ratificações necessárias. A proposta de criar esta zona africana é bastante antiga e foi recomendada na primeira Assembléia dos Chefes de Estado da OAU (Organização da Unidade Africana) por meio da Declaração sobre a Desnuclearização da África em 1964. As discussões sobre a ZLAN Africana perduraram por vários anos, mas só ganharam maior fôlego com a desnuclearização da África do Sul. Este fato confere a esta zona um caráter particular: é composta por um país que desistiu de seu programa nuclear militar. O Tratado foi denominado de Pelindaba, em lembrança ao local onde foram desenvolvidos os artefatos nucleares sul-africanos (Goldblat, 1997, p.24-25).

\footnotetext{
${ }^{12}$ Treaty on a Nuclear-Weapon-Free Zone in Central Asia. Semipalatinsk, 2006. Disponível em:

<http://disarmament.un.org/TreatyStatus.nsf/44e6eeabc9436b78852568770078d9c 0/c851f154c73c8837852572f8005597f1?OpenDocument.> Acesso em: 24 Nov. 2007.
} 
Em 1996, o Tratado de Pelindaba foi aberto para assinaturas. Até junho de 2007, houve 23 ratificações deste tratado, mas o mínimo para sua entrada em vigor são 28 ratificações ${ }^{13}$. Outro ponto que é mister apontar a respeito desta ZLAN é a relutância dos Estados Unidos e da Rússia em assinarem os Protocolos I e II, respectivamente direcionados aos países com territórios na região e às potências nucleares reconhecidas pelo TNP. Os Estados Unidos alegam que sua base militar localizada na Ilha de Diego Garcia, parte do território africano, não está sujeita às determinações da ZLAN Africana. A Rússia, por sua vez, defende que não se sente obrigada a respeitar esta zona porque outra potência nuclear não o faz (Marzo; Almeida, 2006, p.117).

Com o fim da Segunda Guerra Mundial, o mundo foi testemunha de uma verdadeira corrida para o desenvolvimento de tecnologia nuclear para fins bélicos. Entendia-se que, uma vez que os Estados Unidos possuíam a maior capacidade destrutiva da época, como mostraram em Hiroshima e Nagasaki, havia duas opções: desenvolver tecnologia semelhante ou se submeter à influência americana. Como conseqüência, em menos de 20 anos, a antiga União Soviética, o Reino Unido, França e China ${ }^{14}$ desenvolveram e testaram armamentos nucleares.

Nesse contexto, se fez patente a necessidade de desenvolver um regime de não-proliferação eficaz, ou seja, prevenir que mais países desenvolvessem armas nucleares, mas garantindo a possibilidade de desenvolvimento de tecnologia nuclear para fins pacíficos, o que

\footnotetext{
13 Sítio da Unição Africana. Veja <http://www.africaunion.org/root/au/Documents/Treaties/treaties.htm> Acesso em: 01 Nov. 2007.

${ }^{14}$ IAEA factsheet and FAQs on Non-Proliferation key events. Disponível em <http://www.iaea.org/Publications/Factsheets/English/npt_chrono.html> Acesso em: 02 abr. 2010.
} 
seria garantido por meio da submissão dos programas nucleares a salvaguardas ${ }^{15}$. Com essa intenção, foi criada, em 1957, a Agência Internacional de Energia Atômica (AIEA), que deveria, segundo o seu Estatuto, promover a verificação, no sentido de garantir o fim pacífico dos programas nucleares de cada Estado, garantir que as instalações, o transporte do material nuclear e outras atividades relacionadas não representassem riscos para a saúde da população além de prover os meios para a transferência de tecnologia dos países que já possuíam a tecnologia nuclear para aqueles que quisessem desenvolvê-la ${ }^{16}$. A relação desse organismo com a Assembléia Geral das Nações Unidas, e mais especificamente com a Primeira Comissão, se dá por meio de relatórios e da indicação, por parte da Assembléia Geral à submissão dos países aos regimes de salvaguardas da Agência.

Outro aspecto importante do regime de não-proliferação é o Tratado de Não-Proliferação Nuclear (TNP). Segundo esse Tratado, apenas os países detentores de armas nucleares até janeiro de 1967 poderiam ter arsenais nucleares (os cinco países já mencionados). Os demais países deveriam se abster de produzir esse tipo de armamento, mas poderiam desenvolver tecnologia nuclear, desde que submetidos à verificação ${ }^{17}$. Muito embora o TNP tenha um objetivo que até hoje não foi alcançado, o desarmamento geral ${ }^{18}$, não se pode dizer que o

\footnotetext{
${ }^{15}$ Segundo o glossário disponível em <http://www.nti.org/h_learnmore/npttutorial/glossary. html\#safeguards> Acesso em: 02 abr. 2010, salvaguardas são "o monitoramento de material nuclear, com o objetivo de garantir que ele não seja utilizado para fins militares, como implementado pela Agência Internacional de Energia Atômica ou outra organização multilateral."

${ }^{16}$ History of the IAEA. Disponível em: <http://www.iaea.org/About/history.html> Acesso em: 02 abr. 2010.

17 NPT Tutorial. Veja: <http://www.nti.org/h_learnmore/npttutorial/chapter01_02.html> Acesso em: 02 abr. 2010.

18 Treaty on the non-proliferation of nuclear weapons, 1970. Disponível em: <http://www.iaea.org/Publications/Documents/Infcircs/Others/infcirc140.pdf> Acesso em: 02 abr. 2010.
} 
tratado não foi bem sucedido. Apenas Índia, Paquistão e Israel nunca assinaram o tratado, e a Coréia do Norte retirou-se há poucos anos. Ainda assim, é o tratado internacional com o maior número de signatários, e, por haver institucionalizado o regime de salvaguardas, é considerado importantíssimo para o conceito de não-proliferação e desarmamento.

Entretanto, essas iniciativas e outras semelhantes, por mais importantes que sejam para a aspiração de desarmamento global, acabam por não atender às necessidades específicas de certas regiões. O Oriente Médio, por exemplo, reúne características históricas e políticas peculiares, o que torna evidente a necessidade de uma abordagem regional.

Nesse contexto surge, por meio de proposta da União Soviética, a ideia das Zonas Livres de Armas Nucleares (ZLANs). Essas zonas consistem no comprometimento dos países de uma região delimitada com a não produção, aquisição, teste ou posse de armas nucleares em seus territórios, incluindo terras, mares, arquipélagos e águas interiores. ${ }^{19}$ Seu objetivo fundamental seria a garantia da segurança nas regiões e, conseqüentemente, no restante do mundo, por meio da promoção do desarmamento e não-proliferação nuclear, bem como o impedimento do surgimento de novas potências nucleares, por meio da busca pela total eliminação das armas nucleares. ${ }^{20}$

O estabelecimento de uma ZLAN segue alguns passos básicos, ainda que cada zona apresente peculiaridades na sua formação:

\footnotetext{
${ }^{19}$ As águas interiores de um país incluem os mares completamente fechados, os lagos e os rios. Para outros detalhes sugerimos <http://www.armscontrol.org/factsheets/nwfz.asp > Acesso em: 02 abr. 2010.

${ }^{20}$ NWFZ tutorial. Disponível em:

<http://www.nti.org/h_learnmore/nwfztutorial/chapter02_01.html> Acesso em: 02 abr. 2010 .
} 
primeiramente, observam-se iniciativas e consultas regionais; estas são seguidas por negociações entre as partes interessadas; posteriormente há adoção do tratado ainda sem sua forma definitiva; após esse período efetua-se a assinatura do tratado para a criação da ZLAN pelas partes interessadas; logo após, é feita a ratificação do tratado por cada um dos países; e só nesse momento é que o tratado para estabelecimento de uma ZLAN entra em vigor. ${ }^{21}$

O TNP, em seu artigo sétimo, já previa o direito dos países de estabelecer zonas específicas nas quais as armas nucleares poderiam ser banidas, assegurando, contudo, o direito dos países de utilizar energia nuclear com fins pacíficos. As ZLANs atuam de forma a apoiar as condições estabelecidas no TNP, representando um maior comprometimento dos países membros com o desarmamento e a não-proliferação.

Em 1997, a Assembléia Geral das Nações Unidas estabeleceu sete princípios que deveriam nortear a criação de zonas livres de armas nucleares, baseando-se em documentos elaborados desde 1975 no âmbito da ONU. ${ }^{22}$ Em primeiro lugar, qualquer grupo de países, pequeno ou grande, ou até mesmo Estados isoladamente, poderia adotar as medidas necessárias para a criação de uma ZLAN. Em segundo lugar, os arranjos para uma ZLAN deveriam garantir que a região realmente ficasse livre de armas nucleares, ou seja, não só a produção deveria ser proibida, mas também o tráfego e armazenamento. Em terceiro lugar, tal zona só poderia ser criada pelos países da região, e a adesão à mesma somente poderia ocorrer

\footnotetext{
${ }^{21}$ NWFZ tutorial. Disponível em:

<http://www.nti.org/h_learnmore/nwfztutorial/chapter04_01.html> Acesso em: 02 abr. 2010.

${ }^{22}$ Para informações sobre a Resolução da Assembléia Geral das Nações Unidas 3472 B, acesse < http://www.nti.org/h_learnmore/nwfztutorial/pdfs/un_res/3472B,\%201075\%20stu dy\%20of\%20NWFZ.pdf> Acesso em: 02 abr. 2010.
} 
de forma voluntária. Em quarto lugar, a ZLAN deveria contar com a participação de todos os estados da região. Em quinto lugar, para que a ZLAN pudesse funcionar, um mecanismo de verificação deveria ser desenvolvido em caráter obrigatório para todas as partes. Em sexto lugar, o desenvolvimento econômico, social e tecnológico da zona deveria ser garantido por meio da cooperação individual. Por último, o tratado deveria ter duração ilimitada (Goldblat, 1997, p.19).

Apesar da duração ilimitada do tratado, foi estabelecida a possibilidade de que um país de retire do mesmo se assim o desejar. Contudo, essa retirada deve respeitar um prazo para que a necessidade do cumprimento das obrigações estabelecidas no tratado acabe. A verificação do funcionamento das ZLANs, bem como das atividades nucleares de cada Estado membro fica a cargo da AIEA, com a adoção de salvaguardas suplementares às utilizadas em locais sem o status de ZLAN para a fiscalização, tornando o controle internacional sobre as ZLANs muito mais intenso que o feito nas demais regiões.

As ZLANs têm uma vantagem importante no sentido de permitir adaptações às condições regionais, com uma abordagem mais adequada da realidade local e conseqüentemente um melhor resultado no que se refere à instituição da zona e também ao seu funcionamento eficiente. Ainda que haja um regime global eficiente, dificuldades locais poderiam impedir o êxito na busca pelo desarmamento e pela não-proliferação. Soluções para esses entraves são encontradas mais facilmente se pensadas em âmbito regional e se consideradas a características singulares dos atores envolvidos. Nesse sentido, as ZLANs conseguem promover mais facilmente a superação dos entraves locais que se apresentam. Elas incentivam 
ainda a construção de relações de confiança mútua entre seus países membros, diminuindo a sensação de insegurança, além de facilitarem a cooperação em campos diversos, tais como meio ambiente, por meio do controle do impacto dos materiais nucleares no ambiente ${ }^{23}$.

Outro aspecto importante em relação às ZLANs é que os países cuja capacidade nuclear bélica é reconhecida pelo TNP - Estados Unidos, China, Rússia, França e Reino Unido - são convocados, por meio de um protocolo o qual devem assinar e ratificar, a respeitar o status da zona, não podendo utilizar armamento nuclear dentro das mesmas. Desse modo, além dos critérios estabelecidos aos países membros, existiria um comprometimento das potências nucleares com a ZLAN, atingindo um dos objetivos das zonas que é fazer de um ataque a algum dos países membros da ZLAN um evento menos provável além de injustificável.

Os interesses domésticos das potências nucleares fazem com que, mesmo tendo assinado e ratificado os protocolos das ZLANs existentes, esses países tenham muitas restrições a esse mecanismo, reservando-se o direito de utilizar armas nucleares nessas zonas em determinadas situações. Os Estados Unidos, por exemplo, com o objetivo de garantir a livre circulação de seu armamento nuclear por todo o mundo e receoso de limitar sua capacidade de defesa e ataque, estabelecem alguns outros critérios para uma ZLAN, diversos daqueles propostos pela ONU. Entre eles, está a garantia que uma ZLAN não deve diminuir a capacidade dos países em defender-se, nem impedir o tráfego inofensivo, isto é, sem intenções belicosas, pelas águas territoriais dos demais países. Essas medidas 
têm como finalidade permitir que os Estados Unidos ainda exerçam a influência de possuir o maior arsenal nuclear do mundo (Goldblat, 1997, p.19).

A proposição de criação das ZLANs mostra-se complexa, apresentando conflitos de interesses em diversos graus. $\mathrm{O}$ comprometimento limitado das potências nucleares com as ZLANs, bem como os problemas relativos à situação específica de determinados países, mostram que, para serem implementadas de forma efetiva, as zonas têm que estar em equilíbrio com os diversos interesses em questão, como mostram as experiências que já se encontram em andamento. Em áreas como o Oriente Médio, os problemas se mostram de forma ainda mais intensa, levantando uma série de empecilhos ao estabelecimento de uma ZLAN.

\section{Zona Livre de Armas Nucleares no Oriente Médio}

As diversas guerras já deflagradas no Oriente Médio e os constantes conflitos entre as populações - em especial a palestina e a israelense levam à busca pela segurança e pela capacidade de defesa em grande parte dos Estados da região. A suspeita de presença de armamentos nucleares no Oriente Médio resultante de políticas ambíguas quanto à posse das mesmas constitui-se numa das maiores fontes de preocupação relativa à segurança da região. O grande poder de destruição desse tipo de artefato, quando presente em uma região marcada pela instabilidade e pela grande rivalidade entre determinados Estados, requer atenção e cuidado de todo o mundo. A instituição de Zonas Livres de Armas Nucleares mostra-se então uma alternativa ao problema, que para ser entendido de forma mais completa deve ser analisado historicamente, uma vez que as tensões 
no Oriente Médio e a decorrente sensação de insegurança que os Estados da região vivem têm raízes antigas.

Resultado de esforços de vários países no âmbito da ONU, a criação do Estado de Israel, em 1948, foi controversa. Desde 1917, com a Declaração de Balfour ${ }^{24}$, já se discutia o estabelecimento de um Estado judeu na Palestina, e as considerações nesse sentido cresceram a partir de 1922, quando aumentou intensamente o fluxo de judeus para a região. Os conflitos entre judeus e palestinos e as dificuldades do governo britânico de manter a segurança na região, que estava sob seu mandato, aceleraram os esforços no sentido da busca por uma solução definitiva.

Em 1947, a Assembléia Geral das Nações Unidas aprovou a partição do território palestino entre judeus e palestinos árabes, em uma proporção de $48 \%$ e $52 \%$ do território para cada, respectivamente, e definindo a cidade de Jerusalém como zona internacional (A/RES/2/181, p.133). O plano foi bem aceito pelos judeus, mas não pelos países árabes.

Em maio de 1948, Egito, Síria, Jordânia, Líbano e Iraque iniciaram então, um dia após a criação oficial do Estado de Israel, a Primeira Guerra Árabe-Israelense. Apoiados pelos Estados Unidos, os israelenses venceram a guerra e ocuparam grande parte do território destinado aos árabes palestinos. O grande número de palestinos refugiados que se dirigiram aos países árabes próximos traria problemas posteriores à relação já conturbada entre os países da região. Apesar do fim da guerra, as relações entre as nações árabes e Israel continuaram tensas. Em 1949, Israel se torna membro da ONU,

\footnotetext{
${ }^{24}$ Sobre a questão ver The Middle East 1916-2001 : A Documentary Record, disponível em: <http://www.yale.edu/lawweb/avalon/mideast/balfour.htm> Acesso em:02 abr. 2010.
} 
mas os países árabes não o reconheciam como Estado independente (A/RES/3/273).

Em 1956, Gamal Nasser, então presidente do Egito, nacionaliza o Canal de Suez ${ }^{25}$, até então controlado por franceses e ingleses. Com apoio desses dois países, Israel declara guerra ao Egito, visando recuperar o Canal e resolver problemas de fronteiras que tinha com o Egito. A Segunda Guerra Árabe-Israelense, como ficou conhecida, foi vencida por Israel, que ocupou a península do Sinai. Contudo, após resolução da ONU apoiada pelos Estados Unidos e pela então União Soviética, determinou-se a Israel que retornasse aos territórios ocupados em 1949, com estabelecimento de uma força das Nações Unidas (UNEF) pra manter a neutralidade do Canal e da península do Sinai (A/RES/12/1212).

Ao fim da Segunda Guerra Árabe-Israelense, em 1957, dois cientistas dissidentes da Comissão de Energia Atômica Israelense formaram um Comitê (Committee for Denuclearisation of the Arab-Israeli Conflict) que visava à eliminação de artefatos nucleares no conflito árabe-israelense (Pande, 2007). Em 1962, esse Comitê lançou a primeira convocação publica sobre a criação de uma Zona Livre de Armas Nucleares no Oriente Médio. A resposta do governo de Israel foi negativa e o país passou a adotar uma política ambígua a respeito do assunto, uma vez que eles viam na possível obtenção de armas nucleares antes dos demais países do Oriente Médio uma forma de garantir sua segurança e sua presença sem maiores confrontos na região.

As políticas ambíguas, a situação dos refugiados palestinos, bem

${ }^{25}$ Sobre a questão sugerimos Suez Canal Company Nationalisation Law. Disponível em <http://www.sis.gov.eg/En/Land\&people/50th/031700000000000004.htm> Acesso em: 02 abr. 2010. 
como o histórico das guerras anteriores só aumentavam a rivalidade entre os Estados do Oriente Médio. A criação da Organização para a Libertação da Palestina (OLP) em 196426, que visava à criação de um Estado palestino, deflagrou uma guerrilha contra Israel de modo a retomar os territórios ocupados pelo país desde 1948, quando ocorreu a Primeira Guerra Árabe-Israelense. Os países árabes apoiavam as investidas palestinas, gerando ainda mais rivalidade entre Israel e os demais países da região.

Em 1967, após grande acirramento dos conflitos na região, Israel ataca instalações militares egípcias, sírias e jordanianas, iniciando a Terceira Guerra Árabe-Israelense ou Guerra dos Seis Dias. Prevendo ataque por parte dos países árabes, que reuniam exércitos em proximidade a suas fronteiras, Israel lança ataque preventivo que destrói grande parte da força bélica dos países envolvidos. O país mais uma vez sai vitorioso do combate e ocupa um numero ainda maior de territórios palestinos e ainda de países árabes: a Faixa de Gaza, a Península do Sinai, as Planícies de Golan e a Cisjordânia.

A morte de Nasser e a entrada de Sadat na presidência do Egito revigoram os planos egípcios de barrar o expansionismo israelense e de recuperar os territórios perdidos. Em outubro de 1973, Israel foi atacado pelo Egito e pela Síria, dando início à Guerra do Yom Kippur (Dia do Perdão, o correspondente ao Ramadã no calendário islâmico). Esse conflito, que ficou conhecido como a Quarta Guerra Árabe-Israelense, foi deflagrado com a intenção de recuperar os territórios ocupados por Israel durante a guerra de 1967 (Terceira Guerra Árabe-Israelense), que, segundo a Resolução 242 de 1967 do Conselho de Segurança das Nações Unidas, deveriam ser devolvidos,

26 Draft Constitution of the Palestine Liberation Organization. Disponível em: <http://www.thejerusalemfund.org/carryover/documents/draft.html> Acesso em: 02 abr. 2010. 
o que não havia acontecido até o momento. ${ }^{27}$ Embora a guerra tenha parecido favorável ao Egito e à Síria logo no princípio, devido à falta de conhecimento das Forças de Defesa Israelenses (FDI) sobre o ataque, em poucos dias Israel reverteu a situação, deixando clara sua superioridade militar no Oriente Médio. Como forma de retaliação, os países árabes, que controlavam grande parte da produção de petrolífera, iniciaram a primeira crise do petróleo, de modo a atingir principalmente os Estados Unidos e os países europeus que davam suporte a Israel.

A Guerra do Yom Kippur acabou influenciando positivamente a proposta da criação de uma Zona Livre de Armas Nucleares no Oriente Médio. A percepção de que um artefato nuclear poderia ter sido utilizado por parte de Israel durante a guerra deu força à argumentação de especialistas e governantes de que uma Zona Livre de Armas Nucleares era necessária no Oriente Médio.

A situação na região, nessa época, poderia ser descrita da seguinte forma: de um lado, Israel poderia argumentar que sua única garantia de sobrevivência era a manutenção da superioridade militar, inclusive com a produção de armas nucleares. Muito embora esse argumento não fosse utilizado oficialmente, já que Israel mantinha, desde a década de 1950, um discurso ambíguo sobre a posse de armas nucleares, ele servia para legitimar o desenvolvimento de seu programa nuclear, pelo menos entre a população israelense e alguns aliados no Ocidente (Pande, 2007). De outro lado, os países do Oriente Médio, principalmente o Egito, perceberam que Israel poderia ter utilizado algum tipo de armamento nuclear a qualquer

\footnotetext{
${ }^{27}$ UNITED Nations Security Council Resolution 242. Adopted by the Security Council on 22 November $1967 . \quad$ Disponível em: <http://daccess-ddsny.un.org/doc/RESOLUTION/GEN/NR0/240/94/IMG/NR024094.pdf?OpenElement> Acesso em: 02 abr. 2010.
} 
momento durante a guerra. Essa possibilidade de destruição instantânea aumentou o apoio em relação à proposta de criação de uma zona livre de armas nucleares na região.

Em 1974, na Primeira Comissão da Assembléia Geral das Nações Unidas, Irã e Egito apresentaram uma proposta de resolução (A/29/3263) sobre o estabelecimento da Zona Livre de Armas Nucleares (ZLAN) no Oriente Médio. A resolução 3263 foi aprovada, obtendo votos favoráveis dos países nucleares reconhecidos pelo TNP. Israel se absteve, por dois motivos. Se votasse contra, isso seria visto como a confirmação de que seu programa nuclear tinha fins bélicos e, se votasse a favor, o temor que os demais países do Oriente Médio sentiam em relação a Israel diminuiria, o que, sob a perspectiva da posição israelense no Oriente Médio, seria desfavorável ao país (Pande, 2007).

A resolução 3263 apresentava três pontos fundamentais: solicitação de abstenção em relação à produção de armamentos nucleares, pedido de assinatura do TNP e recomendação às cinco nações nucleares reconhecidas pelo Tratado (Estados Unidos, a então União Soviética, a França, a China e o Reino Unido) para que não introduzissem armamentos nucleares na região. Os dois primeiros pontos estavam direcionados principalmente a Israel, já que nenhum dos países da região era considerado possuidor de conhecimento tecnológico suficiente para a construção de armamento nuclear e, além disso, quase todos os países da região já haviam declarado que não tinham a intenção de utilizar tecnologia nuclear para fins bélicos. Entretanto, a postura defensiva ainda era mantida por alguns países, que condicionavam a assinatura do TNP à adesão de Israel ao Tratado. 
Nos anos que se seguiram, o conteúdo das resoluções anuais sobre a ZLAN no Oriente Médio pouco mudou ${ }^{28}$. As orientações permaneceram vagas, sem qualquer sugestão para um processo de negociação. Não existia referência a qualquer ação efetiva para o desarmamento, o que fez da resolução um mero procedimento burocrático, repetido ano após ano na Assembléia Geral, com a finalidade de mostrar que a comunidade internacional prestava atenção à instabilidade do Oriente Médio, mas não propunha qualquer solução ou alternativa. Além disso, a postura representada pela resolução, de que o desarmamento deveria ocorrer antes da estabilização da região, não era apoiada por Israel, o país detentor de armas nucleares na região, o que tornava todo o processo ainda mais ineficiente.

O ano de 1979 destaca-se por sua importância em relação à alteração de muitas das relações políticas existentes até então. A revolução iraniana não só modificou de forma intensa o comportamento interno do país, mas também teve resultantes externas importantes para a dinâmica do conflito, tais como o afastamento do Egito e o engajamento em uma política mais voltada para si e mais distante do ocidente. Outro evento importante do ano foi o tratado de paz assinado entre Egito e Israel, o Acordo de Camp David ${ }^{29}$.

Também em 1979, outras modificações aconteceram na dinâmica das discussões sobre armamentos nucleares dentro da Assembléia Geral. Foi aprovada a resolução A/RES/34/89, apresentada pelo Iraque, que

\footnotetext{
${ }^{28}$ Conforme demonstram as seguintes Resoluções da Primeira Comissão da Assembléia Geral 3263(XXIX), 3474 (XXX), 31/71, 32/82, 33/64, 34/77, 35/147, 36/87 A e B, 37/75, 38/64, 39/54, 40/82, 41/48, 42/28, 43/65, 44/108, 45/52, 46/30, 47/48, 48/71, 49/71, 50/66, $51 / 41,52 / 34,53 / 74,54 /, 55 / 30,56 / 21,57 / 55,58 / 34,59 / 63$ e 60/52.

29 Camp David Accords, September 1978. Disponível em: < http://www.mfa.gov.il/MFA/Peace\%20Process/Guide\%20to\%20the\%20Peace\%20Process/ Camp\%20David\%20Accords> Acesso em: 02 abr. 2010.
} 
tinha por objetivo o estudo do armamento nuclear israelense. A resolução condenava o engajamento de Israel no desenvolvimento de tecnologia nuclear para fins bélicos, solicitava que Israel parasse de desenvolver armamentos nucleares e submetesse suas instalações às salvaguardas da AIEA. Muito embora a posição de Israel fosse criticada dentro das Nações Unidas, a resolução não teve nenhum efeito prático. Na verdade, não só o desenvolvimento desse tipo de tecnologia não cessou em Israel, como esse país não hesitou em atacar outro país que pudesse desenvolver armas nucleares.

Isso ocorreu em 1981, quando Israel, em um ataque surpresa e preciso, destruiu a instalação nuclear de Osirak, no Iraque. Mesmo sendo uma instalação civil, desenvolvida em cooperação com a França e submetida às salvaguardas da AIEA, a inteligência israelense alegou que, em dois anos, o Iraque poderia desenvolver armas nucleares. $\mathrm{O}$ ataque foi condenado pelas Nações Unidas por meio da resolução A/RES/36/27 da Primeira Comissão, de 1981, que condenava as ameaças feitas por Israel a qualquer país considerado inimigo que desenvolva um programa nuclear, advertia Israel contra esse tipo de violação à Carta das Nações Unidas e solicitava ao Conselho de Segurança medidas que impedissem a continuação da política de expansão, ocupação e anexação de Israel (A/RES/36/27). Assim como a resolução que pedia o estudo do armamento nuclear de Israel, esta tampouco teve resultados práticos, principalmente, porque, apesar da condenação no âmbito nas Nações Unidas, muitos países consideraram válida a ação de Israel no sentido de impedir que mais países do Oriente Médio tivessem capacidade de desenvolver armamentos nucleares.

Dessa forma, a Primeira Comissão emitiu resoluções anuais a respeito da condenação ao ataque israelense às instalações nucleares 
iraquianas até 1986 (A/RES/41/12), tratou dos armamentos israelenses até 1993 (A/RES/48/78) e continuou deliberando a respeito da Zona Livre de Armas Nucleares (A/62/251). A cada ano, as resoluções referentes a esse tópico eram aprovadas com praticamente nenhuma modificação no texto. Todos os assuntos foram tratados com relativa superficialidade, devido à situação delicada no Oriente Médio. Evitava-se estipular métodos, dinâmicas de negociação e prazos, principalmente, devido às posições divergentes, quando não antagônicas, dos países envolvidos na questão.

O Secretário-Geral das Nações Unidas, em 1990, submeteu à Assembléia Geral um relatório a respeito das condições para a criação da ZLAN no Oriente Médio, como solicitado na resolução A/RES/43/54 de 1988. No relatório, o SG sugeriu duas configurações geográficas para a ZLAN. Uma com limites na Líbia, a oeste, no Irã, a leste, na Síria, ao norte e no Yêmen ao sul e outra que incluísse todos os países da Liga Árabe, além de Israel e Irã. Entretanto, o SG acrescentou que um limite geográfico deveria ser negociado entre os países envolvidos na questão. Quanto às preocupações geográficas, ainda pesava o fato de que os vizinhos do Oriente Médio (como a exURSS e a Europa) possuíam armas nucleares. O Relatório recomendava que essas regiões não introduzissem armamentos nucleares no Oriente Médio e não armassem a suas fronteiras de forma a não serem percebidos como uma ameaça, com o intuito de evitar que os países do Oriente Médio sentissem a necessidade de possuir armas nucleares para sua defesa (A/45/435, p. 20).

Quanto à adesão ao TNP, o relatório ressaltou que cinco países ainda não o haviam assinado, sendo eles Argélia, Mauritânia, Oman, Emirados Árabes Unidos e Israel. Desse grupo, Argélia já havia colocado seu reator sob salvaguardas da AIEA e, com a exceção de 
Israel, os demais países não possuíam programas nucleares. Os países que haviam assinado o TNP e possuíam reatores nucleares (Egito, Irã e Líbia) já submetiam seus reatores a tratados de salvaguardas da AIEA. Israel, entretanto, não adotava uma política de cooperação com a Agência. Apenas um de seus dois reatores estava sob salvaguarda da Agência. Estima-se que o reator que não é inspecionado regularmente, em Dimona, seja utilizado para a produção de armamentos nucleares. O relatório ressaltava que, para a formação da ZLAN no Oriente Médio, seria necessário que todas as instalações nucleares estivessem sob salvaguardas internacionais apropriadas, não necessariamente sob o TNP, embora isso seja altamente recomendável (A/45/435, p.22).

A criação da ZLAN estaria então condicionada à adesão de Israel a um acordo de salvaguardas que abranja todas as suas instalações, mas a questão tornou-se ainda mais complicada. Isso só poderia acontecer depois que Israel fosse reconhecido por outros Estados da região como um Estado (naquele momento, apenas Egito o reconhecia) e, além disso, Israel teria que se desfazer de seu suposto arsenal nuclear (A/45/435). Outra medida importante para a criação da ZLAN seria a não-proliferação de armas químicas e biológicas, já que outras formas de armas de destruição em massa poderiam ser usadas como pretexto para a manutenção do arsenal nuclear israelense (A/45/435, p.23-25). Quando tratava da Zona, Israel reforçava a necessidade de negociação de seus termos, uma vez que temia a perda de sua capacidade de proteção em meio a um grande número de Estados hostis.

Os países árabes, em especial o Egito, defendem a ZLAN como meio essencial de manutenção da segurança na região e entendem que a zona deve ser pautada pelo cumprimento das regras estabelecidas a 
seu funcionamento. Defendem, inclusive, medidas mais duras e intrusivas de controle nuclear que as adotadas pela AIEA. Desvinculam sua criação de aspectos políticos tais como o reconhecimento de Israel por parte dos demais países, embora acreditem que melhorias relativas à segurança trariam conseqüentemente melhoria às relações políticas. Visam à não utilização das armas nucleares independentemente do grau do conflito na região.

Ainda segundo o relatório, as potências nucleares também têm duas principais responsabilidades no que diz respeito à criação da ZLAN. Em primeiro lugar, tais países devem respeitar a zona, comprometendo-se a não inserir armamentos nucleares na área. Em segundo lugar, devem se comprometer com a cooperação tecnológica aos países da região, para que a ZLAN não pareça um impedimento ao desenvolvimento dos países do Oriente Médio, com o propósito de marginalizar ainda mais a região. Além disso, as potências deveriam utilizar sua influência diplomática para pressionar os países a negociar (A/45/435, p.37-38).

Em 1990, o Egito elabora uma nova proposta para a manutenção da paz e da segurança no Oriente Médio: a Iniciativa Mubarak (GA/DIS/3127). Ela corresponde à transformação de uma ZLAN em uma Zona Livre de Armas de Destruição em Massa (ZLADM) no Oriente Médio. Essa zona teria como regras fundamentais o banimento de qualquer tipo de arma de destruição em massa na zona; o comprometimento de todos os países da região para com a zona; e ainda o respeito às medidas de verificação por parte de todos os Estados componentes da ZLADM.

A Zona deveria envolver todos os Estados da região, mas foi pouco 
aceita. Saddam Hussein constituiu um dos maiores críticos à proposta afirmando que ela desviava a atenção da questão nuclear de Israel e que poderia impossibilitar o intercâmbio de novas tecnologias dentro do Oriente Médio. A reação de Saddam Hussein se dá no contexto do desenvolvimento do programa nuclear iraquiano, interrompido em 1991 pelos bombardeios americanos durante a Guerra do Golfo. A pesar da dificuldade em precisar a natureza de tal programa, em virtude da destruição promovida pelos ataques americanos, há fortes indícios de que o programa nuclear iraquiano era voltado, clandestinamente, para a produção de armas nucleares (Pilat, 1995, p.1225).

A partir de 1994, a ZLADM passa a receber apoio da Síria e da Arábia Saudita, que a defendem como importante fator do processo de paz na região (Pande, 2007). Em 1995, ocorre a estipulação da área da ZLADM, que compreenderia todos os países da Liga Árabe além de Irã e Israel. Contudo, mais uma vez a implementação do projeto não se concretizou, uma vez que obteve apoio restrito, além da usual resistência de Israel. O país anunciou a adoção de alguns dos elementos da ZLADM, mas continuou o argumento de que, para que se estabeleça uma ZLADM na região, seria necessário o estabelecimento da paz e de medidas especificas de funcionamento, de aplicação mútua, bem definidas dessas zonas. Dessa forma, Israel adotou o estabelecimento da zona em seu discurso, tornando-o mais aceitável no meio internacional, mas não se comprometeu a tomar qualquer ação, já que condicionava a criação da ZLADM à paz no Oriente $\mathrm{Médio}^{30}$.

\footnotetext{
30 Blair House Joint Communique: The U.S., Egypt, Israel, Jordan, the Palestinian Authority. Washington, DC, $1995 . \quad$ Disponível em: <http://www.mfa.gov.il/MFA/Archive/Peace+Process/1995/Blair\%20House\%20Joint\%20 Communique\%20-\%2012-Feb-95> Acesso em: 02 abr. 2010; Concluding Statement of the Cairo Summit, 1995. Disponível em: <http://www.mfa.gov.il/MFA/Foreign\%20Relations/Israels\%20Foreign\%20Relations\%20s
} 
Criado para ser um facilitador de negociações, o grupo de trabalho em Controle de Armas e Segurança Regional (CASR) ${ }^{31}$, fundado em 1991 na Conferência da Paz de Madri (Pande, 2007), é um fórum multilateral de busca pela segurança e pela paz. Seu funcionamento, contudo, é limitado pela não participação de alguns dos principais países envolvidos na questão da ZLADM, tais como Irã e Iraque e pelos acordos bilaterais feitos fora do âmbito do grupo.

Um ator problemático e que tem gerado muitos dos atuais conflitos referentes à questão nuclear na região é o Irã. A implantação de usinas de enriquecimento de urânio no país tem preocupado a sociedade internacional, que teme que esse material seja destinado à construção de armas nucleares. Relatórios da AIEA mostram irregularidades no processo de enriquecimento de urânio iraniano e já geraram uma série de condenações e sanções por parte do Conselho de Segurança das Nações Unidas ${ }^{32}$.

As primeiras atividades relativas ao enriquecimento de urânio declaradas pelo Irã foram as realizadas pelo programa de Natanz, em

ince\%201947/1995-1996/Concluding\%20Statement\%20of\%20the\%20Cairo\%20Summit> Acesso em:02 abr. 2010 ; e

Negotiations on Convention Prohibiting Nuclear-Weapon Use called for in text approved by First Committee, Press Release GA/DIS/3127. November 1998. Disponível em: <http://www.un.org/News/Press/docs/1998/19981103.gads3127.html> Acesso em: 02 abr. 2010

${ }_{32}^{31}$ Livre tradução pelos autores.

32 Trata-se das resoluções S/RES/1747 (2007). Disponível em: <http://daccessdds.un.org/doc/UNDOC/GEN/N07/281/40/PDF/N0728140.pdf?OpenEleme nt> Acesso em: 02 abr. 2010; S/RES/1737 (2006). Disponível em: $<$ http://daccessdds.un.org/doc/UNDOC/GEN/NO

6/681/42/PDF/N0668142.pdf?OpenElement> Acesso em: 02 abr. 2010 ; S/RES/1696 (2006). Disponível em: <http://daccessdds.un.org/doc/UNDOC/GEN/N06/450/22/PDF/N0645022.pdf?OpenEleme nt> Acesso em: 02 abr. 2010 
$2003^{33}$. Mesmo afirmando que o propósito dessa experiência seria exclusivamente a obtenção de energia, ou seja, utilização para fins pacíficos, os relatórios oficiais revelam que a condução do processo não seria correspondente a essas funções (GOV/2003/40).

Após as primeiras críticas, o Irã convidou inspetores da AIEA para visita ao país, e assinou um acordo temporário com países da União Européia, tais como Alemanha, França e Grã-Bretanha, garantindo a não expansão nuclear de armamentos, em 2004³. Os Estados Unidos tentaram inúmeras vezes discutir o caso do Irã no Conselho de Segurança das Nações Unidas para a aplicação de sanções, sem sucesso.

Após a conclusão da AIEA sobre a falta de certeza a respeito da não produção de armas nucleares no Irã, as pressões dos países ocidentais começaram a aumentar. Em maio de 2006, uma resolução que propunha uma série de incentivos financeiros foi ofertada pela União Européia e outros países em troca do fim do enriquecimento de urânio em solo iraniano (S/RES/1737), mas o governo alegava ter o direito de produzir energia por meios nucleares por ser signatário do Tratado de Não-Proliferação Nuclear (TNP). Por continuar desafiando os apelos internacionais sobre a questão, o Irã sofreu sanções por parte do Conselho de Segurança (DG 26042005). Ainda que tenha voltado suas atenções ao programa energético, ações paralelas relativas a armas nucleares ainda são tomadas.

O desenvolvimento de tais armamentos em uma região instável, em

\footnotetext{
33 Sobre isso sugerimos: News Center: In Focus: IAEA and Iran. Disponível em: $<$ http://www.iaea.org/NewsCenter/Focus/IaeaIran/iran_timeline.shtml\#february03> Acesso em:. 02 abr. 2010

${ }^{34}$ Sobre isso sugerimos Statement by the Iranian Government and visiting EU Foreign Ministers. Disponível em: <http://www.iaea.org/NewsCenter/Focus/IaeaIran/statement_iran 21102003.shtml> Acesso em: 02 abr. 2010.
} 
que a rivalidade e o conflito são quase constantes, revela-se extremamente preocupante para a sociedade internacional como um todo, além de constituir uma das causas pelas quais Israel alega não adotar a ZLADM.

O Irã, por sua vez, defende a criação da ZLADM nos mesmos moldes dos países árabes: sem relação direta e específica com a política, mas relativa a um conjunto de normas a serem seguidas por todos os estados pertencentes à zona.

Como fator agravante, as relações entre Irã e Israel se mostram cada vez mais tensas. As recentes declarações do presidente do Irã, Mahmoud Ahmadinejad, que constituem ofensas e ameaças ao estado de Israel $^{35}$, só aumentam a rivalidade e a sensação de insegurança entre as nações do Oriente Médio, dificultando o entendimento sobre a questão da criação das ZLADM ou mesmo da ZLAN.

A criação das Zonas Livres de Armas Nucleares no Oriente Médio é extremamente controversa por ser localizada em uma região que possui conjuntos de crenças e valores diferentes, conflitos históricos, bem como diferentes capacidades materiais relativas os países envolvidos. A busca por proteção leva ambos os lados a se tornarem menos flexíveis e menos sujeitos aos acordos para a criação da zona. A proposta de uma Zona Livre de Armas Nucleares, desde sua apresentação pela primeira vez na Assembléia Geral das Nações Unidas até os dias atuais passou por diversos contextos. Em alguns momentos, obteve grande atenção internacional, tanto de políticos quanto de acadêmicos que engrandeceram as vantagens que seriam

\footnotetext{
${ }^{35}$ Sobre isso sugerimos: BBC OnLine. UN condemns Ahmadinejad comments. Disponível em: http://news.bbc.co.uk/2/hi/middle_east/6733487.stm. Acesso em: 05 Dez. 2007.
} 
obtidas se esta ideia fosse adotada. Enquanto que em outros momentos, esta proposta esteve totalmente desacreditada pela comunidade internacional.

Para entender as atuais discussões acerca desta proposta e sua relevância, é necessário, primeiramente, construir o ambiente em que elas ocorrem. Isso somente é possível mesclando dois elementos: os diferentes motivos que levam os países a buscarem o desenvolvimento de armas nucleares e os novos acontecimentos em relação à proliferação nuclear e ao Oriente Médio.

Segundo Gawdat Bahgat (2005,p.405-411), são cinco as motivações que levam os países à decisão de desenvolver armas nucleares. Bahgat faz a ressalva de que estes pontos são complementares e que um só ponto não pode explicar a decisão como um todo. O primeiro motivo seria a globalização e o imperativo tecnológico. Nos primeiros anos que sucederam o desenvolvimento da tecnologia nuclear militar pelos Estados Unidos e URSS, estes dois países evitaram qualquer envolvimento com atividades de transferência de tecnologia nuclear para os países do Oriente Médio. No entanto, o atual momento diferencia-se muito deste primeiro, principalmente porque a globalização facilitou enormemente a transferência e acessibilidade à tecnologia nuclear militar. Os países não mais necessitam da ajuda técnica de uma das potências nucleares reconhecidas no TNP. Um exemplo desta situação era o mercado negro de tecnologias e materiais nucleares comandado por A. Q. Khan, chefe do programa nuclear paquistanês. Nesse contexto, alguns analistas acreditam que os países que dominam o conhecimento técnico-científico para a produção de uma arma nuclear certamente não hesitarão em desenvolver projetos dessa natureza. 
O segundo motivo é a abordagem psicológica e cognitiva dos líderes governamentais. Neste caso, o Oriente Médio apresenta exemplos inegáveis da relação entre líderes centralizadores e a ambição de desenvolver armas nucleares, como: Nasser no Egito, Gaddafi na Líbia, Hussein no Iraque, Shan no Irã e Ben-Gurion em Israel. O terceiro é o modelo da política doméstica e as dinâmicas internas. Estas dinâmicas são especialmente influenciadas por organizações domésticas, como entidades estatais ligadas à produção de energia nuclear, unidades dentro das Forças Armadas e alguns políticos, segundo Scott D. Sagan (apud Bahgat, 2005, p.405-411).

A quarta motivação é o prestígio e o orgulho nacionais. Este ponto é particularmente importante nas dinâmicas no Oriente Médio, porque somente uma nação, Israel, possui um programa nuclear para fins militares e armas nucleares em seu domínio. Além disso, esta nação não só não compartilha a mesma religião ou cultura da maioria da população da região, como também apresenta uma política de atrito constante com seus vizinhos. Sendo assim, em muitos países da região, como Iraque, Irã e Egito, utilizaram-se os sentimentos de inferioridade e vitimização de suas populações para atrelar a posse de armas nucleares à obtenção de prestígio internacional e aumento do orgulho nacional. Dessa forma, tenta-se legitimar essa decisão.

Por fim, a quinta motivação é a segurança e a liberdade para buscar uma política exterior independente. No Oriente Médio, a questão da segurança passa inevitavelmente pelo conflito Árabe-Israelense e a instabilidade no Golfo Pérsico, que muito contribuíram para tornar a posse de armas nucleares um chamativo caminho para adquirir superioridade sobre os outros estados. Alem disso, esta posse surge como um elemento mantenedor de uma política externa 
independente de qualquer imposição exterior, visto que a presença americana na região aumentou nos últimos anos e, conseqüentemente, sua influência sobre os países lá localizados.

É fundamental observar também que a questão aqui tratada é influenciada por novos acontecimentos vindos de diferentes níveis de análise. Os principais desdobramentos recentes que contribuem para a formação do atual contexto no qual se enquadram as discussões acerca do estabelecimento de uma Zona Livre de Armas Nucelares podem ser divididos em três níveis: o nível global, que envolve as atuais discussões em relação ao TNP e a agressiva política americana de combate à proliferação nuclear após o 11 de setembro; o nível regional, que abrange os novos desdobramentos na proposta de uma Zona Livre de Armas Nucleares no Oriente Médio e a nova rodada de negociações de paz entre israelenses e palestino; e o nível estatal, em que se pode ressaltar os últimos passos do programa nuclear iraniano e sua repercussão mundial.

Como já foi comentado, o TNP representa o código legal básico acerca da proliferação de armas nucleares no âmbito global. Os últimos anos possibilitaram um enfoque sobre o problema da aplicabilidade de suas políticas e trouxeram um sentimento de descrença em relação a este tratado. Não há dúvidas de que os casos do Irã e da Coréia do Norte colocaram essa questão em foco, uma vez que desafiaram frontalmente o conjunto de princípios e normas incorporado no TNP, e pouco foi possível fazer para impedir que levassem em frente seus programas nucleares. O programa nuclear norte-coreano ${ }^{36}$, particularmente, demonstrou a incapacidade de

\footnotetext{
${ }^{36}$ A Coréia do Norte anunciou sua retirada do TNP em janeiro de 2003. Atualmente, participa de conversações hexapartites (Coréia do Norte, Coréia do Sul, Estados Unidos, Federação Russa, Japão e R.P. China) sobre a desativação e o desmantelamento de seu programa nuclear.
} 
atuação do TNP em caso de retirado do país do mesmo, enquanto que as atividades nucleares do Irã mostram a dificuldade de detectar atitudes em desacordo com as políticas do tratado e a inexistência de um plano de ação a ser seguido em relação a países que se recusam a cooperar (Choe, 2006, p.38).

No nível global, ainda pode-se acrescentar que a política americana mais agressiva em relação à proliferação de armas nucleares após os ataques terroristas de 11 de setembro de 2001 tem grande influência sobre as configurações atuais do debate sobre não proliferação nuclear em todo o mundo. A administração Bush engajou-se em evitar que "rogue states"37, ou organizações terroristas, sejam supridos com tecnologia ou armas nucleares. Tendo em vista esse objetivo, estão dispostos a utilizar como instrumentos extremos de não-proliferação a diplomacia coerciva ou a força militar. Os americanos argumentam que a atual situação difere totalmente daquela existente durante a Guerra Fria, pois a "segurança" garantida pela Destruição Mútua Assegurada (DMA) foi substituída pelo risco das armas nucleares caírem em mãos de terroristas ou estados irresponsáveis que teriam menos motivos para hesitar na decisão de usá-las (Bahgat, 2005, p.418-420). A invasão do Iraque, em 2003, baseada na suspeita de posse de armas de destruição em massa por parte dos iraquianos, enquadra-se nesta política americana mais agressiva.

Em escala regional, a mais recente proposta de Zona Livre de Armas Nucleares no Oriente Médio apresentada pelo Egito à Agência Internacional de Energia Atômica demonstrou uma maior desconfiança em relação a esta ideia, principalmente, por parte de

\footnotetext{
37 "Rogue States", resumidamente, são Estados que ameaçam a manutenção da paz por meio do apoio a grupos terroristas e à proliferação de armas de destruição em massa.
} 
alguns países europeus. Diferentemente das propostas anteriores, que geralmente não são objeto de um numero significativo de abstenções, esta recebeu 53 votos a favor, dois contra, provenientes de Israel e Estados Unidos, e surpreendentes 43 abstenções, vindas de alguns países europeus e em desenvolvimento ${ }^{38}$. Este resultado surge num ambiente de maior preocupação européia em relação ao programa nuclear iraniano e aumento da politização da questão nuclear no Oriente Médio ${ }^{39}$.

Adicionalmente, pode-se citar como outro acontecimento atual no nível regional a retomada das negociações de paz entre israelenses e palestinos. Esta dinâmica representa a convergência dos últimos desdobramentos na disputa israelense com seus vizinhos e a recente decisão americana de transformar estas negociações de paz em uma das prioridades de política externa do final do atual mandato do presidente Bush. Espera-se que as negociações de Annapolis (novembro de 2007) possam render bons frutos no longo prazo para a dinâmica de atritos na região, embora não tenham sinalizado resultados no curto prazo $^{40}$.

Passando para o nível estatal, devem-se destacar os últimos desdobramentos do programa nuclear do Irã. As autoridades iranianas continuam a defender a natureza pacífica deste programa, embora a AIEA ainda não a tenha confirmado, e a declarar que é um absurdo pedir que parem de enriquecer urânio, uma vez que

\footnotetext{
${ }^{38}$ Mais informações em New Zealand Press Association. Egypt hits at EU for UN Nuclear Vote Abstention. Factiva. Disponível em: <http://www.iaea.org/Archives/templates/jsp/pa ges/pi/NewsCenter_search.jsp?paging=1\&currentPage=55\&FQuery=> Acesso em: 22 Set. 2007.

39 Informações adicionais em IAEA Passes Resolution Calling for A Nuclear-WeaponsFree Middle East. Factiva. Disponível em: <http://www.iaea.org/Archives/templates/jsp/pa ges/pi/NewsCenter_search.jsp?paging=1\&currentPage=55\&FQuery=> Acesso em: 21 Set. 2007.

${ }^{40}$ Sobre isso sugerimos: BBC Online. Bush launches new Mid-East talks. Disponível em: <http://news.bbc.co.uk/2/hi/middle_east/7117744.stm> Acesso em: 01 Dez. 2007.
} 
possuem este direito segundo o TNP. Por outro lado, as potências européias e os Estados Unidos argumentam que o Irã está longe de cooperar satisfatoriamente com a AIEA e pressionam por sanções mais duras contra este país. Alguns analistas acreditam que em breve estas sanções sejam aprovadas pelo Conselho de Segurança, mas a Federação Russa e a República Popular da China ainda não estão totalmente convencidas da urgência destas medidas. Se isso não acontecer, especula-se que serão decididas sanções econômicas no âmbito da União Européia ${ }^{41}$.

Tendo em vista tudo que foi apresentado, pode-se entender mais profundamente o atual contexto em que se desenvolvem as discussões acerca do estabelecimento de uma Zona Livre de Armas Nucleares, a importância desta proposta para a estabilidade da região, bem como os argumentos utilizados pelos países envolvidos, que pouco se alteraram nas últimas décadas. Por um lado, os israelenses defendem que a zona livre de armas nucleares deve ser colocada em prática somente após o alcance da paz e estabilidade na região. Por outro, os árabes e iranianos continuam a argumentar que esta zona tem que ser implantada o quanto antes, para diminuir as tensões e desconfianças na região (Bahgat, 2005, p.165-167).

Em contraposição, as potências ocidentais tornaram-se mais descrentes em relação à efetividade da proposta e agressivas em relação à proliferação nuclear no Oriente Médio. Além disso, vale ressaltar que muitas vezes estas mesmas potências adotam dois pesos e duas medidas para tratarem dos programas nucleares iraniano e israelense. Costuma-se reprimir o primeiro, enquanto prefere-se deixar de lado o ambíguo programa nuclear israelense.

41 Sobre essa questão sugerimos: BBC Online. Iran rejects EU 'disappointment'. Disponíevl em: <http://news.bbc.co.uk/2/hi/middle_east/7122440.stm> Acesso em: 01 Dez. 2007. 
Por fim, é necessário ainda acrescentar a importância do debate sobre o desarmamento nuclear. Segundo Michael MccGwire, a adoção do explícito objetivo de alcançar um mundo livre de armas nucleares lidaria muito melhor com a proliferação de armas nucleares do que um mundo em que vivemos, onde as potências nucleares tentam evitar a proliferação sem o comprometimento com o desarmamento (MccGwire, 1994, p.222). Baseado neste argumento, não se pode deixar de discutir o papel das potências nucleares como incentivadoras ou não da implementação de uma Zona Livre de Armas Nucleares no Oriente Médio.

\section{Conclusão}

Tendo em vista a delicada conjuntura política do Oriente Médio, uma solução para risco da proliferação nuclear que leve em consideração os aspectos diferenciados da região, como uma Zona Livre de Armas Nucleares desenhada unicamente para o Oriente médio, pode ser uma alternativa interessante. No entanto, um primeiro passo fundamental rumo à criação de tal zona seria a adesão dos países da região aos instrumentos internacionais existentes de controle de não-proliferação, por meio da assinatura e ratificação do TNP e submissão ao regime de salvaguardas da AIEA. Tal medida teria por objetivo o fortalecimento do TNP e da AIEA no Oriente Médio, além do estabelecimento de um cenário propício a uma melhor dinâmica de negociação entre os envolvidos no conflito.

Além do fortalecimento do regime de não-proliferação já existente, é preciso incentivar também que cada país desenvolva planos de ação específicos para o controle de materiais e instalações nucleares que se adaptem às suas dinâmicas internas, e enfoque de maneira abrangente a atuação de atores não-estatais, que têm estado envolvidos nos conflitos que tomaram conta da região nos últimos 
anos, a exemplo da Al Qaeda, Hezbollah, entre outros.

A atuação das potências nucleares regionais e globais na questão é outro ponto importante nas considerações da criação de uma ZLAN no Oriente Médio. Uma postura colaborativa de tais potências deveria ser guiada pela diminuição da ambigüidade entre apoio e condenação de países à margem do regime de não-proliferação. $\mathrm{O}$ diálogo, tanto no Oriente Médio quanto seus vizinhos e as potências nucleares, deve caminhar no sentido de garantir a segurança daqueles que não possuem armamentos nucleares, fazendo valer, desta forma, a Negative Security Assurances (em uma tradução livre: Garantia Negativa de Segurança), institucionalizada pela resolução 984 do Conselho de Segurança das Nações Unidas, que assegura que os estados não-nucleares signatários do TNP não correm o risco de serem atacados por estes armamentos ${ }^{42}$.

Após a discussão do histórico das Zonas Livres de Armas Nucleares e a proposta de criação de uma ZLAN no Oriente Médio, é possível perceber que as negociações para este fim são travadas basicamente por uma questão: o que deve vir primeiro, a paz no Oriente Médio ou o compromisso com o desarmamento, especialmente nuclear, na região? De fato, a paz no Oriente Médio só poderá ser alcançada quando houver condições para que uma série de outros tipos de insegurança, que vão além da desnuclearização de qualquer Estado que possua armamentos nuclear na região, sejam solucionadas, tais como questões da escassez de água e alimentos em algumas áreas, a má distribuição de renda, as animosidades entre as diversas religiões e facções da mesma religião, as identidades nacionais definidas pelo ódio a outras nacionalidades. No entanto, exatamente por estas e uma série de outras questões que não permitem que a presença de armamentos nucleares no Oriente Médio seja analisada sob a ótica do nuclear deterrence realizada por atores racionais, a desnuclearização

${ }^{42}$ Embora não exista um tratado formal a respeito da NSA, as cinco potências nucleares no TNP já emitiram declarações afirmando o compromisso em não atacar com armamento nucleares os demais países signatários do TNP. Tais declarações são reconhecidas pela resolução 984 do Conselho de Segurança das Nações Unidas. 
da região deve ser um objetivo a ser buscado com empenho por toda a comunidade internacional - ONU, AIEA, potências, países do Oriente Médio e seus vizinhos.

\section{Referências Bibliográficas:}

AFRICAN Union. Official Documents. Disponível em: $<$ http://www.africa-nion.org/Official_documents/Treaties_\%20Conv entions_\%20Protocols/offTreaties_Conventions_\&_Protocols.htm> Acesso em: 01 nov. 2007.

ARMS Control Association. Nuclear-Weapon-Free Zones (NWFZ) At a Glance. s/d. Disponível em: <http://www.armscontrol.org/factsheets/nwfz.asp> Acesso em: 02 abr. 2010.

ASEAN. Treaty on the Southeast Asia Nuclear Weapon-Free Zone. 1995. Disponível em: <http://www.aseansec.org/2082.htm> Acesso em: 01 nov. 2007.

BAHGAT, Gawdat. Nuclear Proliferation and the Middle East. The Journal of Social, Political and Economic Studies, v. 30, n. 4, p. 401 423, 2005.

BAHGAT, Gawdat. Prospects for a Nuclear Weapons Free Zone in the Middle East. World Affairs, v. 169, n. 4, p. 161-168, 2007.

BBC Online. Bush launches new Mid-East talks. 2007. Disponível em: <http://news.bbc.co.uk/2/hi/middle_east/7117744.stm> Acesso em: 01 dez. 2007. 
BBC Online. Iran rejects EU 'disappointment'. 2007. Disponível em: $<$ http://news.bbc.co.uk/2/hi/middle_east/7122440.stm>. Acesso em: 01 dez. 2007.

BBC OnLine. UN condemns Ahmadinejad comments. 2007. Disponível em:<http://news.bbc.co.uk/2/hi/middle_east/6733487.stm> Acesso em: 05 dez. 2007.

CHOE, Julia. Problems of Enforcement: Iran, North Korea and NPT. Harvard International Review, v. 28, n. 2, p. 38-41, 2006.

EGYPT State Information Service. Suez Canal Company Nationalisation Law. Disponível em: $<$ http://www.sis.gov.eg/En/Lan d\&people/50th/031700000000000004.htm> Acesso em: 02 abr. 2010.

GOLDBLAT, Jozef. Nuclear-Weapon-Free-Zone: a history and assessment. The Nonproliferation Review, v. 4, n. 3, p. 18-32, 1997.

INTERNATIONAL Atomic Energy Agency. Disponível em: $<$ http://www.iaea.org>. Acesso em: 02 abr. 2010.

INTERNATIONAL Atomic Energy Agency. History of the IAEA. Disponível em: <http://www.iaea.org/About/history.html>. Acesso em: 02 abr. 2010.

INTERNATIONAL Atomic Energy Agency. IAEA and Iran. Disponível em: <http://www.iaea.org/NewsCenter/Focus/IaeaIran/Ira n_timeline.shtml\#february03>. Acesso em: 02 abr. 2010.

INTERNATIONAL Atomic Energy Agency. Treaty on the NonProliferation of Nuclear Weapons (NPT). s/d. Disponível em: 
<http://www.iaea.org/Publications/Documents/Treaties/npt.html>. Acesso em: 02 abr. 2010.

INTERNATIONAL Atomic Energy Agency. IAEA Passes Resolution Calling for A Nuclear-Weapons-Free Middle East. Factiva. s/d. Disponível em: <http://www.iaea.org/Archives/templates/jsp/pages/ pi/NewsCenter_search.jsp?paging=1\&currentPage=55\&FQuery $=>$ Acesso em: 21 set. 2007.

INTERNATIONAL Atomic Energy Agency. 2003. GOV/2003/40. Disponível em: <http://www.iaea.org/Publications/Documents/Board /2003/gov2003-40.pdf>. Acesso em: 02 abr. 2010.

INTERNATIONAL Atomic Energy Agency. Statement by the Iranian Government and visiting EU Foreign Ministers. 2003. Disponível em: $<$ http://www.iaea.org/NewsCenter/Focus/IaeaIran/statement_iran211 02003.shtml>. Acesso em: 02 abr. 2010.

INTERNATIONAL Atomic Energy Agency. DG 26042005. 2005. Disponível em: <http://www.iaea.org/NewsCenter/Statements/2005/e bsp2005n005.html>. Acesso em: 02 abr. 2010.

ISRAEL Ministry of Foreign Affairs. Camp David Accords. 1978. Disponível em: < http://www.mfa.gov.il/MFA/Peace\%20Process/Gu ide\%20to\%20the\%20Peace\%20Process/Camp\%20David\%20Accord>. Acesso em: 02 abr. 2010.

ISRAEL Ministry of Foreign Affairs. Blair House Joint Communique The U.S., Egypt, Israel, Jordan, the Palestinian Authority. 1995. Disponível em: <http://www.mfa.gov.il/MFA/Archive/Peace+Process /1995/Blair\%20House\%20Joint\%20Communique\%20-\%2012-Feb-95> 
Acesso em: 02 abr. 2010.

ISRAEL Ministry of Foreign Affairs. Concluding Statement of the Cairo Summit. 1995. Disponível em: <http://www.mfa.gov.il/MFA/Fo reign\%20Relations/Israels\%20Foreign\%20Relations\%20since\%201947 /1995-1996/Concluding\%20Statement\%20of\%20the\%20Cairo\%20Sum mit> Acesso em: 02 abr. 2010.

JERUSALEM Fund. The Draft Constitution of the Palestine Liberation Organization. 1963. Disponível em: <http://www.thejerusa lemfund.org/www.thejerusalemfund.org/carryover/documents/draft. html>. Acesso em: 02 abr. 2010.

MARZO, Marco Antonio S.; ALMEIDA, Silvio Gonçalves de. A Evolução do controle de Armas nucleares: desarmamento e nãoproliferação. Rio de Janeiro: Editora Ciência Moderna Ltda., 2006.

MCCGWIRE, Michael. Is there a future for nuclear weapons? International Affairs, v. 70, n. 2, p. 211-228, 1994.

MINISTÉRIO das Relações Exteriores. Tratado de Tlatelolco. 1994. Disponível em: <http://www2.mre.gov.br/dai/tlatelolco.htm>. Acesso em: 24 nov. 2007.

NUCLEAR Threat Initiative. Nuclear-Weapon-Free-Zones. Objectives and Purposes of NWFZs. s/d. Disponível em:<http://www.nti.org/h_learnmore/nwfztutorial/chapter02_02.htm 1>. Acesso em: 02 abr. 2010.

NUCLEAR Threat Initiative. Nuclear-Weapon-Free-Zones. Establishing a Nuclear-Weapon-Free Zone. s/d. Disponível em: 
$<$ http://www.nti.org/h_learnmore/nwfztutorial/chapter04_01.html $>$. Acesso em: 02 abr. 2010.

NUCLEAR Threat Initiative. Nuclear-Weapon-Free-Zones. Definition and Characteristics of a NWFZ. s/d. Disponível em: $<$ http://www.nti.org/h_learnmore/nwfztutorial/chapter02_01.html> Acesso em: 02 abr. 2010.

NUCLEAR Threat Initiative. Nuclear-Weapon-Free-Zones. Glossary. s/d. Disponível em: <http://www.nti.org/h_learnmore/npttutorial/gl ossary.html> Acesso em: 02 abr. 2010.

NUCLEAR Threat Initiative. Nuclear-Weapon-Free-Zones. What is the Non-Proliferation Treaty? s/d. Disponível em: $<$ http://www.nti.or g/h_learnmore/npttutorial/chapter01_02.html $>$ Acesso em: 02 abr. 2010.

PANDE, Savita. Nuclear Weapon-Free Zone in the Middle East. Strategic Analysis. 1998. Disponível em: $<$ http://www.ciaonet.org/olj/sa/sa_98pns02.html $>$ Acesso em: 18 nov. 2007.

PILAT, Joseph F. Iraq and the Future of Nuclear Proliferation: the Roles of Inspections and Treaties. Science, v. 255, n. 5049, p. 12241230, 1992.

REUTERS. Egypt hits at EU for UN Nuclear Vote Abstention. 2007. Disponível em: $<$ http://www.reuters.com/article/idUSL21105695200 70921>. Acesso em: 22 set. 2007.

UNITED Nations. ResolutionA/RES/2/181. 1947. Disponível em: 
<http://www.un.org/documents/ga/res/2/ares2.htm> Acesso em: 02 abr. 2010.

UNITED Nations. Resolution 273 (III). 1948. Disponível em: $<$ http://www.un.org/documents/ga/res/3/ares3.htm>. Acesso em: 02 abr. 2010.

UNITED Nations. Resolution A/RES/12/1212. 1957. Disponível em: $<$ http://www.un.org/documents/ga/res/12/ares12.htm>. Acesso em: 02 abr. 2010.

UNITED Nations. Resolution 242/1967. 1967. Disponível em: $<$ http://daccessdds.un.org/doc/RESOLUTION/GEN/NR0/240/94/IMG /NR024094.pdf?OpenElement >. Acesso em: 02 abr. 2010.

UNITED Nations. Resolution 3263(XXIX). 1974. Disponível em: $<$ http://www.un.org/documents/ga/res/29/ares29.htm>. Acesso em: 02 abr. 2010.

UNITED Nations. Resolution 3472 (XXX) B. 1975. Disponível em: $<$ http://www.nti.org/h_learnmore/nwfztutorial/pdfs/un_res/3472B, \% 201075\%20study\%20of\%20NWFZ.pdf>. Acesso em: 02 abr. 2010.

UNITED Nations. Resolution A/RES/34/89. 1979. Disponível em: $<$ http://www.un.org/documents/ga/res/34/ares34.htm>. Acesso em: 02 abr. 2010.

UNITED Nations. Resolution A/RES/36/27. 1981. Disponível em: $<$ http://www.un.org/Depts/dhl/res/resa36.htm>. Acesso em: 02 abr. 2010 . 
UNITED Nations. Resolution A/RES/41/12. 1986. Disponível em: $<$ http://www.un.org/Depts/dhl/res/resa41.htm>. Acesso em: 02 abr. 2010.

UNITED Nations. Agenda A/45/435. 1990. Disponível em: $<$ http://documents-ddsny.un.org/doc/UNDOC/GEN/N90/257/74/img /N9025774.pdf?OpenElement>. Acesso em: 02 abr. 2010.

UNITED Nations. Resolution A/RES/48/78. 1993. Disponível em: $<$ http://www.un.org/Depts/dhl/res/resa48.htm>. Acesso em: 02 abr. 2010.

UNITED Nations. Press Release GA/DIS/3127. Negotiations on Convention Prohibiting Nuclear-Weapon Use Called for in Text Approved by First-Committee. 1998. Disponível em: <http://www.un.org/News/Press/docs/1998/19981103.gads3127.html> Acesso em: 02 abr. 2010.

UNITED Nations. Treaty on the non proliferation of nuclear weapons (NPT). 2005. Disponível em: <http://www.un.org/events/np t2005/npttreaty.html> Acesso em: 02 abr. 2010.

UNITED Nations.Resolution S/RES/1696. 2006. Disponível em: <http://www.un.org/Docs/sc/unsc_resolutions06.htm>. Acesso em: 02 abr. 2010.

UNITED Nations.Resolution S/RES/1737. 2006. Disponível em: <http://www.un.org/Docs/sc/unsc_resolutions06.htm>. Acesso em: 02 abr. 2010.

UNITED Nations. Agenda A/62/251. 2007. Disponível em: 
$<$ http://www.un.org/ga/search/view_doc.asp?symbol=A/62/251\&Lan $\mathrm{g}=\mathrm{E}>$. Acesso em: 02 abr. 2010.

UNITED Nations.Resolution S/RES/1747. 2007. Disponível em: <http://www.un.org/Docs/sc/unsc_resolutions07.htm> Acesso em: 02 abr. 2010.

UNITED Nations. The United Nations Disarmament Yearbook. New York: Office for Disarmament Affairs, 2007.

UNITED Nations Disarmament. Treaty on a Nuclear-Weapon-Free Zone in Central Asia. 2006. Disponível em: $<$ http://disarmament.un.org/TreatyStatus.nsf/44e6eeabc9436b7885256 8770078d9c0/c851f154c73c8837852572f8005597f1?OpenDocument>. Acesso em: 24 nov. 2007.

YALE Law School. The Avalon Project. The Middle East 1916-2001: A Documentary Record. 2008. Disponível em: $<$ http://avalon.law.yale.edu/subject_menus/mideast.asp $>$. Acesso em: 02 abr. 2010. 